\title{
2D and 3D imaging of the relationship between maxillary sinus and posterior teeth
}

\author{
Gina Delia Roque-Torres ${ }^{1}$, Laura Ricardina Ramirez-Sotelo ${ }^{1}$, Solange Maria de Almeida ${ }^{1}$, \\ Gláucia Maria Bovi Ambrosano ${ }^{2}$, Frab Norberto Bóscolo ${ }^{1}$
}

\author{
${ }^{1}$ Universidade Estadual de Campinas - UNICAMP, Piracicaba Dental School, Department of Oral Diagnosis, Piracicaba, SP, Brazil \\ ${ }^{2}$ Universidade Estadual de Campinas - UNICAMP, Piracicaba Dental School, Department of Community and Preventive Dentistry, Area of Biostatistics,
}

Piracicaba, SP, Brazil

\begin{abstract}
Aim: To compare the qualitative and quantitative information yielded by imaging modalities on the evaluation of the relationship between the maxillary sinus and the apices of posterior teeth. Methods: Three oral radiologists examined 109 panoramic radiographs and cone-beam computed tomography (CBCT) images obtained from a digital archive. A total of 1,875 apices were classified according to their topographic relationship in both imaging modalities. Agreements between the two imaging techniques were examined statistically. The evaluation was repeated in $25 \%$ of the sample to statistically evaluate the intraobserver agreement, with a 30 -day interval. Results: The values found in the Kappa test for qualitative assessment and the intraclass correlation coefficient (ICC) for quantitative assessment showed nearly perfect and excellent correlation, respectively. Regarding the correlation between the two images, the Kappa test in the quality assessment showed a slight correlation between the palatal roots of the right first molars and second molars. Moreover, the quantitative evaluation by ICC showed poor agreement for the palatal roots of the left first molar and second molar, as well as for the buccomesial of the right second molars and for the buccodistal of the left second molars. Conclusions: There is low correlation between panoramic radiography and $\mathrm{CBCT}$ when roots are in contact or above the maxillary sinus floor. A high level of agreement was observed when roots are below the maxillary sinus floor.
\end{abstract}

Keywords: maxillary sinus; tooth apex; cone-beam computed tomography; radiography, panoramic.

\section{Introduction}

The inferior sinus wall is a curved structure that is extended between adjacent

Received for publication: April 23, 2015 Accepted: June 09, 2015

Correspondence to: Gina Delia Roque-Torres Universidade Estadual de Campinas Faculdade de Odontologia de Piracicaba Avenida Limeira, 901 Bairro Areão

CEP: 13414-903 Piracicaba - SP Brazil Phone +55 1921065327 Fax: +55 1934210144 E-mail: ginart87@gmail.com teeth, or individual roots in about half of the population, creating elevations in the antral surface or protrusions of the root apices into the sinus cavity; its floor is formed by the alveolar process of the maxilla ${ }^{1}$. In cases where the roots of the posterior maxillary teeth may project into the maxillary sinus, the thickness of the sinus floor is markedly reduced or absent ${ }^{2}$.

Information concerning the relationship between the root apices and the inferior wall of the maxillary sinus is crucial in diagnosing and treating sinus pathosis, periodontal or periapical infection of upper premolars and molars, which can spread to the maxillary sinus causing sinusitis ${ }^{1,3}$. These anatomical relationships can decide the spread of buccal cellulites ${ }^{4-5}$. 
Also in the diagnosis and treatment plan for a dental implant $^{6}$ a positive correlation between the length of the projection roots on the maxillary sinus in panoramic radiographs and the amount of pneumatization after extraction was found. Sinus expansion after extraction can greatly decrease bone height available for implant placement ${ }^{2}$. Furthermore, extraction of these same teeth may result in oroantral fistula or root displacement into the sinus cavity, which are usual complications ${ }^{7}$. Likewise, endodontic procedures and therapies can cause an endo-antral syndrome ${ }^{6-}$ ${ }^{8}$, the spread of pulpal disease beyond supporting tissues into the maxillary sinus causing acute or chronic sinusitis ${ }^{1,5,8}$. Finally, it affects orthodontic tooth movements, especially in movements of intrusion or bodily movement of teeth across the sinus floor ${ }^{9-10}$.

Panoramic radiograph are frequently used to evaluate teeth and patterns of the craniofacial skeleton, serving as a guide for their diagnosis and planning ${ }^{11}$. Furthermore, some ghost images are formed on the opposite site of the object, mesiodistal and vertical enlargement, adding a limitation to evaluating the anatomic correlation between tooth roots and alveolar bone when using only a panoramic radiography ${ }^{12}$. In addition, clinical indications involving the roots of teeth are mostly endodontic or related and require single dental $\mathrm{X}$-ray as the best imaging modality with minimal radiation dose. Most drawbacks of single dental X-ray are similar to those of panoramic radiography.

Cone beam computed tomography (CBCT) would potentially provide information needed for prosthetic treatment planning, implant selection, and/or surgical placement ${ }^{13}$. CBCT examinations are also reliable for linear measurement ${ }^{14}$. Furthermore, despite the difference in radiation between $\mathrm{CBCT}$ and $2 \mathrm{D}$ images, it has been demonstrated that decreasing the field of view (FOV) helps reducing radiation dose, resulting in 2.7 to $23 \mathrm{mSv}$ for a panoramic and 34-89 $\mathrm{Sv}$ for the $\mathrm{CBCT}^{13}$. Both modalities have less radiation than Computed Tomography $(\mathrm{CT})^{15}$.

While some authors ${ }^{16-17}$ have investigated the relationship between the roots of maxillary teeth and the maxillary sinus floor by $\mathrm{CT}$, others ${ }^{11-12}$ have compared $\mathrm{CT}$ and panoramic radiograph imaging. Recent studies ${ }^{18-21}$ evaluate this relationship using $\mathrm{CBCT}$, and perform classification or measurements without establishing a comparison to the twodimensional technique. Hassan $(2010)^{22}$ investigated the reliability of both periapical radiographs and panoramic radiography for exact detection of tooth root protrusion in the maxillary sinus by correlating the results with CBCT. Ok et al. (2014) $)^{23}$ evaluated the relationship between each root of maxillary premolars and molars and the maxillary sinus floor. According to Shahbazian et al. (2014) ${ }^{3}$, CBCT provides more information regarding these topographic relationships for maxillary posterior teeth than panoramic radiography.

The present study was performed to understand the relationship between the maxillary sinus floor and the apices of maxillary posterior teeth by comparing the qualitative and quantitative information provided by two imaging methods: panoramic radiography and $\mathrm{CBCT}$.

\section{Material and methods}

One hundred and nine dental records of subjects selected from the digital archive of Oral Radiology Center of Piracicaba Dental School (UNICAMP, Brazil) were selected after approval of the protocol by the local ethics committee for research on human subjects (protocol \#059/2011). The selected subjects comprised 78 women and 31 men, with a mean age of 22 years (range: from 18-30), regardless of ethnic group, social class or other socioeconomic characteristics.

From the dental record of each subject, a pair of panoramic radiograph and CBCT (dated within 1 month) was selected. Each pair depicted the root apices of the maxillary posterior teeth and the sinus floor. The digital panoramic radiographs were all produced by the same Orthopantomograph machine DOP 100 (Instrumentarium Corp, Imaging Division, Tuusula, Finland), by using settings of $2 \mathrm{mAs}, 57-60 \mathrm{kVp}$, with time exposure of 17.6 seconds and were stored digitally. All CBCT scans were produced by the Classic i-CAT unit (Imaging Sciences International, Hatfield, PA, USA), using settings of $8 \mathrm{~mA}, 120 \mathrm{kV}, 40$ second of acquisition time, voxel size of $0.3 \mathrm{~mm}$ and $23 \times 17 \mathrm{~cm}$ field of view. It was acknowledged that the images had another purpose in the time they were taken. The digital panoramic radiographs were imported to be evaluated in the software Radioimp - Radiomemory (Belo Horizonte, MG, Brazil), and the files of DICOMS of tomographic images were imported into Ez3D software (Korea).

Images were selected considering a high-level technical standard (i.e. appropriate sharpness, density and contrast), clearly showing the maxillary posterior teeth apices and the sinuses floor. The inclusion criteria were subject to the following: complete permanent dentition, no evidence of supernumerary teeth, no presence of some sort of pathology or radiographic evidence of teeth with marked disruption in the apical third of the root.

Each root of the first and second premolars and the first and second molars was used in the qualitative and quantitative evaluations. An assessment of the topographic relationship of each root to the maxillary sinus floor was conducted in both panoramic radiograph and in CBCT images by three oral radiologists who acted as evaluators of the research for at least 3 years. Under dim light conditions, they blindly evaluated the images as described by Sharan and Madjar (2006) ${ }^{11}$, using the following scoring system: 0 , the apices of the root is not in contact with the cortical borders of the sinus; 1 , the apices of the root is in contact with the cortical borders of the sinus; 2, the root is projected laterally to the sinus cavity, and an apices is in contact with the cortical borders sinus; 3 , the apices is projecting in the sinus cavity, and; 4, the maxillary sinus has a buckle that goes round the root of the tooth, but its apices is just in contact with the cortical borders sinus. All cases in which the qualitative assessment of the root was scored 0 were given a positive number, those with 1, 2, 4 were numbered as $0 \mathrm{~mm}$, and those with qualitative assessment 3 were given a negative number as a means of quantitatively assessing 
the length of the apical part of the root superior to the sinus inferior wall (Figures 1-3).

In the panoramic radiograph, this quantitative assessment represented the radiographic projection of the root in the sinus cavity, and in the $\mathrm{CBCT}$, it represented the protrusion of the root into the sinus (Figures 2-3). The quantitative assessment was made from the root apices to the superior part of the cortical inferior wall of the sinus along the longitudinal axis of the root (Figures 1-2) in both images. The oral radiologists were allowed to adjust brightness, contrast and magnification for better observation of anatomic structures in all the views, and choose just one view to make the measurement and scale in the case of CBCT. For cases in which the teeth had fused roots, the evaluators gave the same measures and scale for all the roots. Thirty days after the first evaluation, $25 \%$ of the samples were reevaluated in order to assess intraobserver agreement.

Through the correlation between panoramic radiography and $\mathrm{CBCT}$, the mode for qualitative assessments and the average for quantitative obtained by the three observers in both imaging modalities, for all dental roots was calculated.

To calculate statistical differences between the two types of images, based on both qualitative and quantitative assessment, Kappa test and intraclass correlation coefficient (ICC) were performed, respectively, with a significance level of $5 \%$, using the statistical package SAS ${ }^{\circledR}$ (Statistical Analysis Software Institute Inc. Cary, NC, USA) and SPSS ${ }^{\circledR}$ version 9.2 (Statistical Package for the Social Sciences) version 20.0 , respectively.

\section{Results}

The values obtained for the intra- and inter-observer assessment were good to excellent for Kappa and excellent for ICC, considering the evaluations for qualitative and quantitative assessments, respectably, for both images. Comparison of the qualitative assessment of maxillary tooth roots in relationship to the sinus ûoor in panoramic radiography and $\mathrm{CBCT}$ images

The level of agreement shown for the qualitative assessment according to the Kappa test of all roots of the right and left side, with a confidence interval of $95 \%$, was as following: slight agreement $(0-0.20)$ for the palatal roots of the right first molars and second molar; fair $(0.21-0.40)$ for the buccal roots of the second premolars, buccal and palatal the left first premolars, palatal root of the left first molar, buccomesial and buccodistal of the right first molars and second molars; moderate $(0.41-0.60)$ for the buccal root of the right first premolar, buccomesial and bucco distal of the left first molar; substantial $(0.60-0.80)$ for the palatal root of the right first premolars (Figure 1, Table 1).

Regarding the quantitative assessment of the relationship between the maxillary tooth roots and the sinus ûoor in panoramic radiography and $\mathrm{CBCT}$ images, there was poor correlation (ICC <0.4) according to the ICC for the palatal root of the left first molars, buccomesial and palatal of the right second molars, buccodistal and palatal of the left second molar; satisfactory correlation $(0.4 \mathrm{~d}$ " ICC $<0,75)$ for the buccal root of the first and second premolars on the right,

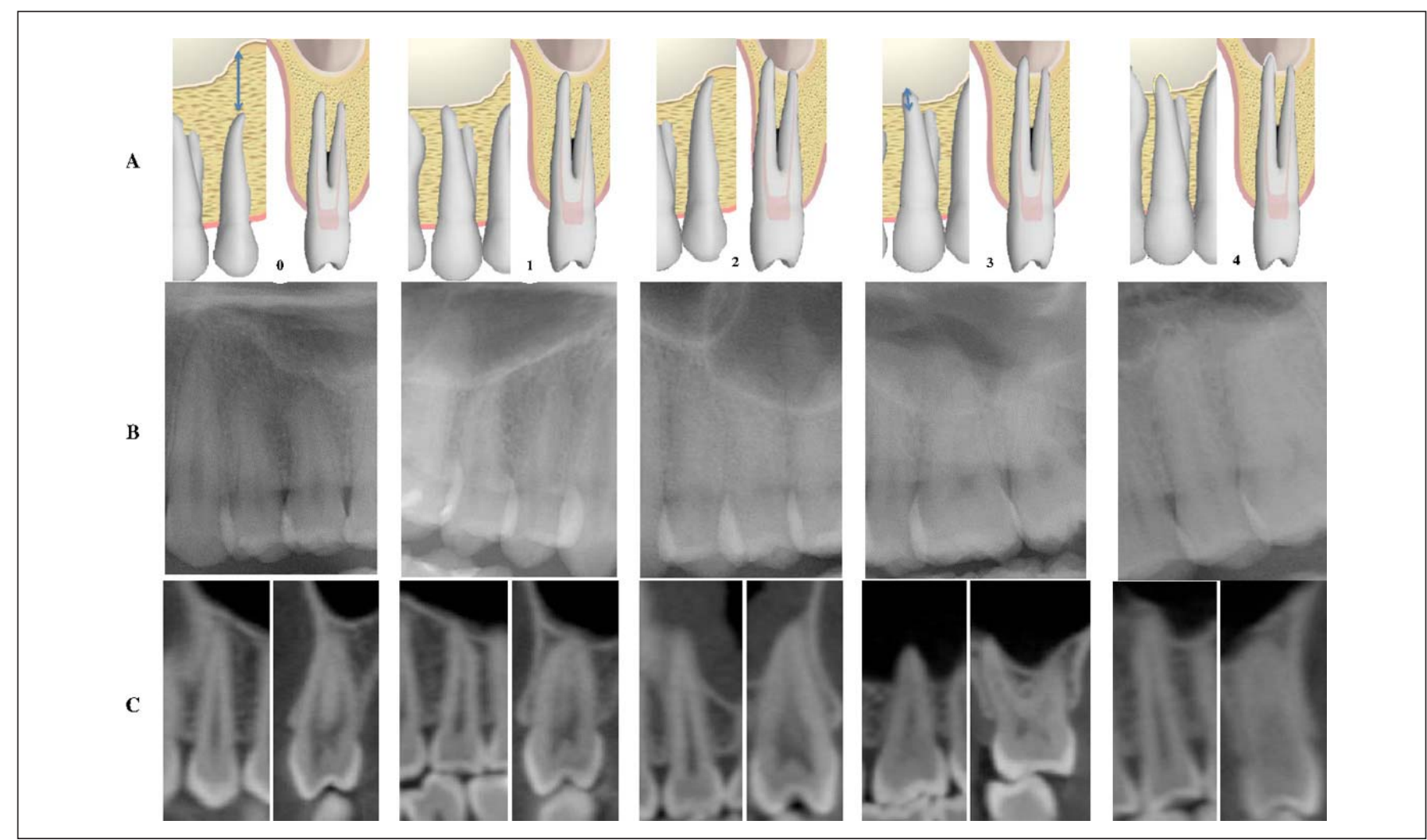

Fig. 1. Qualitative assessment of the 5 scales of the maxillary posterior teeth roots in relation to the inferior wall of the sinus. A: Schematic drawing of the images (sagittal and coronal view). B: Illustrations on the panoramic images. C: Illustrations on the CBCT (sagittal and coronal view). 

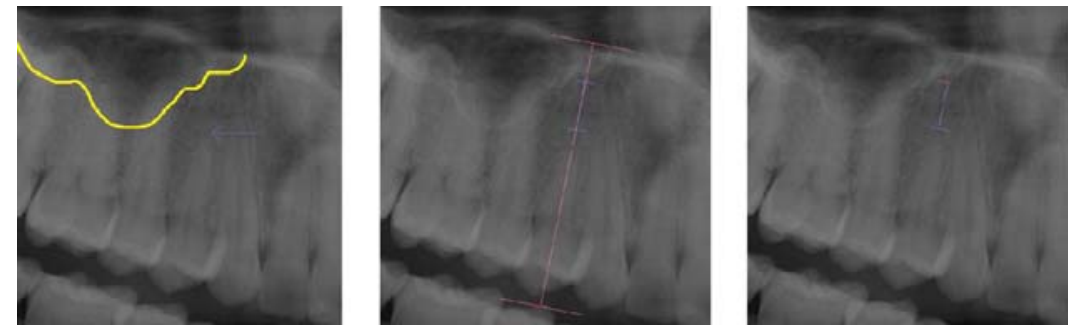

Fig. 2. Quantitative assessment of the panoramic radiograph images.
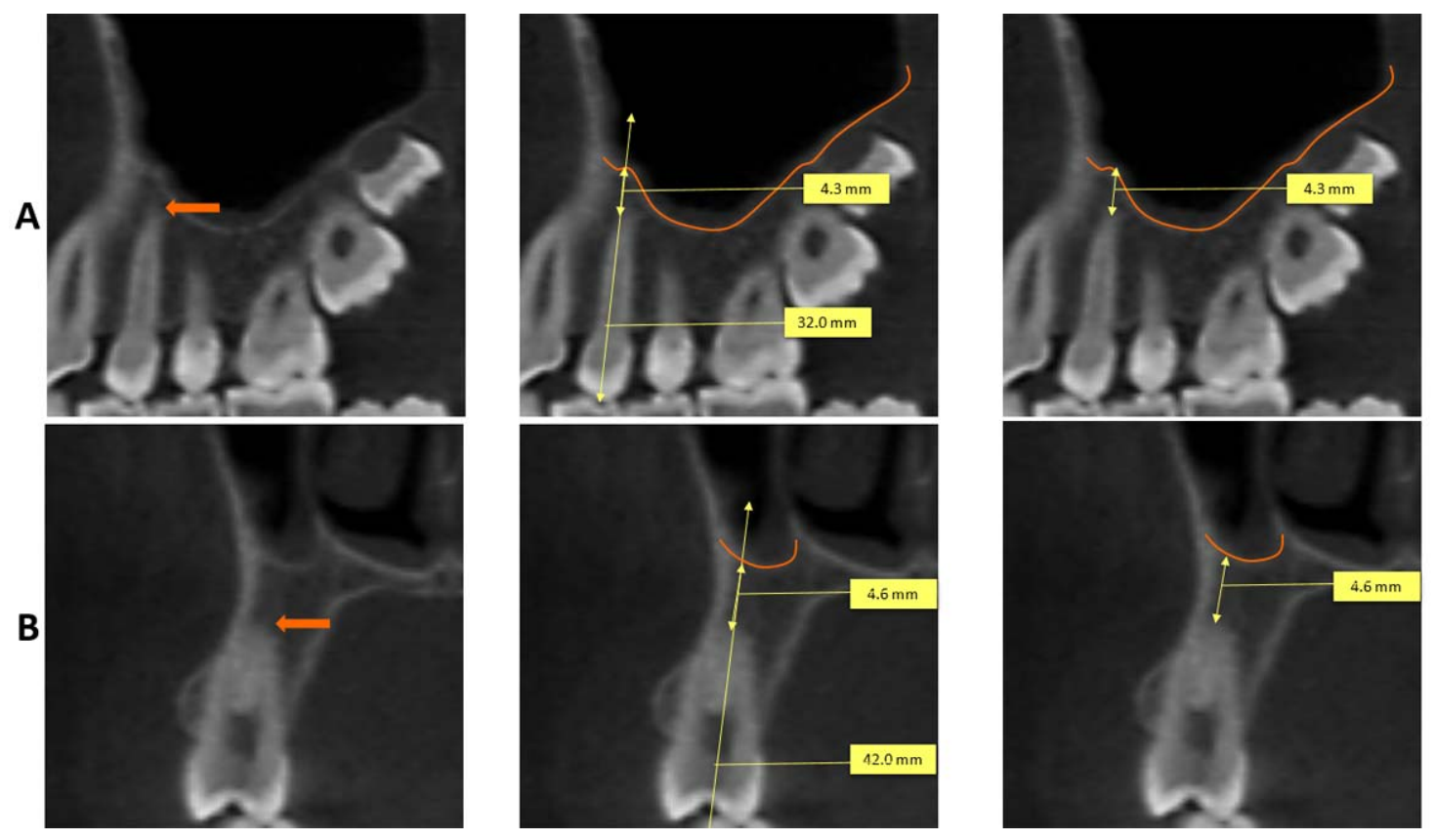

Fig. 3. Quantitative assessment of the CBCT images. A: Sagittal view. B: Coronal view.

Table 1. Level of agreement between both images modalities by Kappa test of all roots, with a confidence interval of $95 \%$ (Qualitative assessment).

\begin{tabular}{|c|c|c|c|c|c|c|c|}
\hline \multicolumn{2}{|c|}{ Right } & \multirow{2}{*}{$\begin{array}{c}\mathbf{k} \\
0.3468\end{array}$} & \multirow{2}{*}{$\begin{array}{c}\mathrm{Cl}-95 \% \\
0.2259-0.4676\end{array}$} & \multicolumn{2}{|c|}{ Left } & \multirow{2}{*}{$\begin{array}{c}\mathbf{k} \\
0.2726\end{array}$} & \multirow{2}{*}{$\begin{array}{c}\mathrm{Cl}-95 \% \\
0.1354-0.4099\end{array}$} \\
\hline \multirow{3}{*}{$2 \mathrm{M}$} & $\mathrm{BM}$ & & & \multirow{3}{*}{$2 \mathrm{M}$} & BM & & \\
\hline & BD & 0.2859 & $0.1680-0.4039$ & & BD & 0.3454 & $0.2165-0.4743$ \\
\hline & $\mathbf{P}$ & 0.0828 & $0.0219-0.1438$ & & $\mathbf{P}$ & 0.0856 & $0.0261-0.1450$ \\
\hline \multirow{3}{*}{$1 \mathrm{M}$} & BM & 0.3676 & $0.2671-0.4681$ & \multirow{3}{*}{$1 \mathrm{M}$} & BM & 0.4142 & $0.2998-0.5287$ \\
\hline & BD & 0.3521 & $0.2332-0.4710$ & & BD & 0.4292 & $0.3191-0.5392$ \\
\hline & $\mathbf{P}$ & 0.1659 & $0.0809-0.2509$ & & $\mathbf{P}$ & 0.2140 & $0.1373-0.2907$ \\
\hline \multirow{2}{*}{ 2PM } & B & 0.3374 & $0.2381-0.4366$ & \multirow{2}{*}{ 2PM } & B & 0.3772 & $0.2767-0.4778$ \\
\hline & $\mathbf{P}$ & - & -- & & $\mathbf{P}$ & - & - \\
\hline \multirow{2}{*}{ 1PM } & B & 0.4595 & $0.3368-0.5823$ & \multirow{2}{*}{ 1PM } & B & 0.3158 & $0.1963-0.4353$ \\
\hline & $\mathbf{P}$ & 0.6071 & $0.4721-0.7421$ & & $\mathbf{P}$ & 0.2879 & $0.0436-0.5323$ \\
\hline
\end{tabular}

k-Kappa Coefficient, Cl-Confidence Interval, M-molar, PM-premolar, BM-buccomesial, BD-buccodistal, P-palatal, B-buccal. *most of the $2^{\text {nd }}$ pm had only a single root. 
Table 2. Level of agreement between both images modalities according to the Intraclass Correlation Coefficient (quantitative assessment).

\begin{tabular}{|c|c|c|c|c|c|c|c|}
\hline \multicolumn{2}{|c|}{ Right } & \multirow{2}{*}{$\frac{\text { ICC }}{0.383}$} & \multirow{2}{*}{$\begin{array}{c}\mathrm{Cl}-95 \% \\
0.099-0.578\end{array}$} & \multicolumn{2}{|c|}{ Left } & \multirow{2}{*}{$\begin{array}{c}\text { ICC } \\
0.507\end{array}$} & \multirow{2}{*}{$\begin{array}{c}\mathrm{Cl}-95 \% \\
0.284-0.661\end{array}$} \\
\hline \multirow{3}{*}{$2 \mathrm{M}$} & BM & & & \multirow{3}{*}{$2 \mathrm{M}$} & BM & & \\
\hline & BD & 0.408 & $0.102-0.607$ & & BD & \multirow{2}{*}{$\begin{array}{l}0.323 \\
0.186\end{array}$} & \multirow{2}{*}{$\begin{array}{c}0.031-0.531 \\
-0.147-0.454\end{array}$} \\
\hline & $\mathbf{p}$ & 0.28 & $-0.183-0.591$ & & $\mathbf{P}$ & & \\
\hline \multirow{3}{*}{$1 \mathrm{M}$} & $\mathrm{BM}$ & 0.581 & $0.181-0.764$ & \multirow{3}{*}{$1 \mathrm{M}$} & BM & 0.614 & $0.044-0.812$ \\
\hline & BD & 0.658 & $0.435-0.784$ & & BD & 0.642 & $0.341-0.789$ \\
\hline & $\mathbf{P}$ & 0.403 & $-0.209-0.722)$ & & P & 0.278 & $-0.164-0.612$ \\
\hline \multirow[b]{2}{*}{ 2PM } & B & 0.681 & $0.193-0.844$ & \multirow[b]{2}{*}{ 2PM } & B & 0.779 & $0.125-0.912$ \\
\hline & $\mathbf{P}$ & 0.929 & $0.688-0.984$ & & $\mathbf{p}$ & 0.964 & $0.868-0.990$ \\
\hline \multirow{2}{*}{ 1PM } & B & 0.682 & $-0.122-0.876$ & \multirow{2}{*}{ 1PM } & B & 0.717 & $-0.109-0.894$ \\
\hline & $\mathbf{P}$ & 0.821 & $0.272-0.931$ & & $\mathbf{P}$ & 0.736 & $0.014-0.898$ \\
\hline
\end{tabular}

ICC-Intraclass Correlation Coefficient, Cl-Confidence Interval, M-molar, PM-premolar, BM-buccomesial, BD-buccodistal, P-palatal, B-buccal.

Table 3. Mean, standard deviation, minimum and maximum values from the quantitative assessment in both images modalities.

\begin{tabular}{|c|c|c|c|c|c|c|c|c|c|c|c|}
\hline & Right & & Mean & Std Dev. & Max. & Min. & Left & Mean & Std. Dev. & Max. & Min. \\
\hline \multirow{6}{*}{$2 \mathrm{M}$} & CBCT & $\mathrm{BM}$ & 0.00 & 0.92 & 4.90 & -5.00 & \multirow{6}{*}{$2 \mathrm{M}$} & -0.42 & 1.33 & 2.00 & -8.10 \\
\hline & PAN & & -0.78 & 1.62 & 3.40 & -6.41 & & -0.71 & 1.51 & 5.08 & -5.47 \\
\hline & СВCT & BD & -0.30 & 1.53 & 7.60 & -4.40 & & -0.02 & 0.94 & 3.70 & -3.90 \\
\hline & PAN & & -0.76 & 1.69 & 3.84 & -5.80 & & -0.54 & 1.50 & 6.16 & -3.66 \\
\hline & СВCT & P & 0.78 & 2.04 & 9.50 & -3.70 & & 0.46 & 1.84 & 7.10 & -10.20 \\
\hline & PAN & & -2.77 & 2.05 & 3.58 & -7.46 & & -3.04 & 2.02 & 6.02 & -7.54 \\
\hline \multirow{6}{*}{$1 \mathrm{M}$} & CBCT & BM & 0.42 & 1.63 & 10.20 & -3.30 & \multirow{6}{*}{$1 \mathrm{M}$} & 0.25 & 1.61 & 9.70 & -4.20 \\
\hline & PAN & & -0.86 & 1.96 & 5.47 & -5.51 & & -1.18 & 1.84 & 4.69 & -4.77 \\
\hline & CBCT & BD & 0.34 & 1.58 & 7.50 & -3.40 & & 0.07 & 1.40 & 7.20 & -3.80 \\
\hline & PAN & & -0.45 & 1.82 & 4.73 & -4.75 & & -0.77 & 1.55 & 4.97 & -4.57 \\
\hline & СBCT & $\mathbf{P}$ & 0.53 & 2.12 & 8.30 & -4.70 & & 0.34 & 1.57 & 5.70 & -3.50 \\
\hline & PAN & & -3.11 & 2.52 & 4.12 & -8.93 & & -3.60 & 2.26 & 3.13 & -8.10 \\
\hline \multirow{4}{*}{ 2PM } & CBCT & B & 1.80 & 2.99 & 13.50 & -3.10 & \multirow{4}{*}{$2 \mathrm{PM}$} & 1.46 & 2.77 & 10.80 & -3.00 \\
\hline & PAN & & -0.10 & 2.44 & 7.84 & -4.65 & & -0.31 & 2.47 & 7.56 & -5.95 \\
\hline & СBCT & $\mathbf{P}$ & 2.27 & 4.20 & 12.00 & 0.00 & & 0.78 & 2.39 & 8.30 & 0.00 \\
\hline & PAN & & 1.12 & 3.31 & 7.36 & -2.41 & & 0.37 & 2.20 & 6.97 & -2.49 \\
\hline \multirow{4}{*}{$1 \mathrm{PM}$} & CBCT & B & 6.48 & 5.23 & 22.10 & 0.00 & \multirow{4}{*}{ 1PM } & 6.16 & 5.44 & 21.30 & -2.00 \\
\hline & PAN & & 2.57 & 3.24 & 11.60 & -5.42 & & 2.28 & 3.39 & 12.50 & -4.69 \\
\hline & CBCT & $\mathbf{P}$ & 6.53 & 5.70 & 19.90 & -2.60 & & 7.00 & 5.37 & 20.20 & 0.00 \\
\hline & PAN & & 3.71 & 3.85 & 13.03 & -2.41 & & 3.51 & 3.71 & 14.33 & -2.87 \\
\hline
\end{tabular}

Std Dev.-Standard deviation, Max- Maximum values, Min- Minimum values, M-molar; PM-premolar, CBCT-Cone beam computed tomography, PAN-Panoramic radiography, BM-buccomesial, BD-buccodistal, P-palatal, B-buccal.

buccal and palatal of the left first premolars, buccodistal for the right second molar, buccomesial for the left second molar, buccomesial and buccodistal for the left first molar and for all the roots of the right first molars; and excellent correlation (ICC e" 0.75) for the palatal roots of the first and second premolars on the right and all the roots to the left second premolar (Figures 2-3, Table 2)

As much as $819(43.7 \%)$ out of 1,875 roots seemed to penetrate the maxillary sinus on the panoramic radiographs, but this number dropped to $80(3.1 \%)$ in $\mathrm{CBCT}$, which indicates that $\mathrm{CBCT}$ and panoramic radiographs had a poor correlation when roots were in contact or within the maxillary sinus floor (Table 3). Based on the average of the quantitative and qualitative assessments of all roots comparing both imaging modalities, it was observed that the buccomesial and buccodistal roots of the second molars were found to be 
Table 4. Incidence and classifications of the vertical relationship between the inferior wall of the maxillary sinus and the roots of the maxillary teeth comparing CBCT and panoramic radiography images (aualitative assessment).

\begin{tabular}{|c|c|c|c|c|c|c|c|c|c|c|c|c|c|}
\hline & & & & & & & & Panoramic $\mathbf{R}$ & adiography & & & & \\
\hline & & & & 0 & 1 & 2 & 3 & 4 & 0 & 1 & 2 & 3 & 4 \\
\hline & & & 0 & $6(0.32 \%)$ & $2(0.11 \%)$ & $0(0 \%)$ & $0(0 \%)$ & $0(0 \%)$ & $17(0.91 \%)$ & $9(0.48 \%)$ & $0(0 \%)$ & $0(0 \%)$ & $0(0 \%)$ \\
\hline & & & 1 & $6(0.32 \%)$ & $84(4.48 \%)$ & $0(0 \%)$ & $21(1.12 \%)$ & $1(0.05 \%)$ & $4(0.21 \%)$ & $59(3.15 \%)$ & $0(0 \%)$ & $15(0.80 \%)$ & $1(0.05 \%)$ \\
\hline & & $\sum_{\infty}$ & 2 & $1(0.05 \%)$ & $7(0.37 \%)$ & $1(0.05 \%)$ & $17(0.91 \%)$ & $1(0.05 \%)$ & $0(0 \%)$ & $23(1.23 \%)$ & $1(0.05 \%)$ & $62(3.31 \%)$ & $0(0 \%)$ \\
\hline & & & 3 & $1(0.05 \%)$ & $8(0.43 \%)$ & $0(0 \%)$ & $12(0.64 \%)$ & $0(0 \%)$ & $0(0 \%)$ & $0(0 \%)$ & $0(0 \%)$ & $9(0.48 \%)$ & $0(0 \%)$ \\
\hline & & & 4 & $0(0 \%)$ & $21(1.12 \%)$ & $2(0.11 \%)$ & $25(1.33 \%)$ & $2(0.11 \%)$ & $0(0 \%)$ & $7(0.37 \%)$ & $0(0 \%)$ & $11(0.59 \%)$ & $0(0 \%)$ \\
\hline & & & 0 & $7(0.37 \%)$ & $14(0.75 \%)$ & $0(0 \%)$ & $0(0 \%)$ & $0(0 \%)$ & $10(0.53 \%)$ & $15(0.80 \%)$ & $0(0 \%)$ & $5(0.27 \%)$ & $0(0 \%)$ \\
\hline & & & 1 & $11(0.59 \%)$ & 74 (3.95\%) & $3(0.16 \%)$ & $22(1.17 \%)$ & $3(0.16 \%)$ & $3(0.16 \%)$ & $39(2.08 \%)$ & $0(0 \%)$ & $16(0.85 \%)$ & $0(0 \%)$ \\
\hline & $\sum_{N}$ & 㟧 & 2 & $0(0 \%)$ & $11(0.59 \%)$ & $3(0.16 \%)$ & $28(1.49 \%)$ & $0(0 \%) \sum_{-1}$ & $1(0.05 \%)$ & $17(0.91 \%)$ & $4(0.21 \%)$ & $90(4.80 \%)$ & $0(0 \%)$ \\
\hline & & & 3 & $0(0 \%)$ & $6(0.32 \%)$ & $0(0 \%)$ & $6(0.32 \%)$ & $0(0 \%)$ & $0(0 \%)$ & $3(0.16 \%)$ & $1(0.05 \%)$ & $8(0.43 \%)$ & $0(0 \%)$ \\
\hline & & & 4 & $0(0 \%)$ & $9(0.48 \%)$ & $2(0.11 \%)$ & $15(0.80 \%)$ & $3(0.16 \%)$ & $0(0 \%)$ & $1(0.05 \%)$ & $1(0.05 \%)$ & $3(0.16 \%)$ & $1(0.05 \%)$ \\
\hline & & & 0 & $3(0.16 \%)$ & $12(0.64 \%)$ & $0(0 \%)$ & $23(1.23 \%)$ & $0(0 \%)$ & $4(0.21 \%)$ & $17(0.91 \%)$ & $1(0.05 \%)$ & $14(0.75 \%)$ & $0(0 \%)$ \\
\hline & & . & 1 & $1(0.05 \%)$ & $14(0.75 \%)$ & $0(0 \%)$ & $60(3.20 \%)$ & $1(0.05 \%)$ & $0(0 \%)$ & $16(0.85 \%)$ & $0(0 \%)$ & $22(1.17 \%)$ & $0(0 \%)$ \\
\hline ש & & $a$ & 2 & $0(0 \%)$ & $8(0.43 \%)$ & $2(0.11 \%)$ & $85(4.53 \%)$ & $0(0 \%)$ & $2(0.11 \%)$ & $2(0.11 \%)$ & $0(0 \%)$ & $122(6.51 \%)$ & $0(0 \%)$ \\
\hline & & & 3 & $0(0 \%)$ & $0(0 \%)$ & $0(0 \%)$ & $4(0.21 \%)$ & $0(0 \%)$ & $0(0 \%)$ & $1(0.05 \%)$ & $0(0 \%)$ & $14(0.75 \%)$ & $0(0 \%)$ \\
\hline & & & 4 & $0(0 \%)$ & $0(0 \%)$ & $0(0 \%)$ & $3(0.16 \%)$ & $1(0.05 \%)$ & $0(0 \%)$ & $0(0 \%)$ & $0(0 \%)$ & $1(0.05 \%)$ & $0(0 \%)$ \\
\hline & & & 0 & $49(2.61 \%)$ & $12(0.64 \%)$ & $14(0.75 \%)$ & $2(0.11 \%)$ & $0(0 \%)$ & $127(6.77 \%)$ & $18(0.96 \%)$ & $21(1.12 \%)$ & $2(0.11 \%)$ & $0(0 \%)$ \\
\hline & & & 1 & $1(0.05 \%)$ & $39(2.08 \%)$ & $21(1.12 \%)$ & $40(2.13 \%)$ & $0(0 \%)$ & $4(0.21 \%)$ & $17(0.91 \%)$ & $7(0.37 \%)$ & $13(0.69 \%)$ & $0(0 \%)$ \\
\hline & & $\infty$ & 2 & $1(0.05 \%)$ & $4(0.21 \%)$ & $2(0.11 \%)$ & $21(1.12 \%)$ & $0(0 \%)$ & $0(0 \%)$ & $1(0.05 \%)$ & $1(0.05 \%)$ & $6(0.32 \%)$ & $0(0 \%)$ \\
\hline & & & 3 & $0(0 \%)$ & $0(0 \%)$ & $0(0 \%)$ & $5(0.27 \%)$ & $0(0 \%)$ & $0(0 \%)$ & $0(0 \%)$ & $0(0 \%)$ & $1(0.05 \%)$ & $0(0 \%)$ \\
\hline & 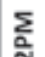 & & 4 & $0(0 \%)$ & $0(0 \%)$ & $0(0 \%)$ & $3(0.16 \%)$ & $0(0 \%) \sum_{a}$ & $0(0 \%)$ & $0(0 \%)$ & $0(0 \%)$ & $0(0 \%)$ & $0(0 \%)$ \\
\hline & & & 0 & $3(0.16 \%)$ & $1(0.05 \%)$ & $0(0 \%)$ & $0(0 \%)$ & $0(0 \%)$ & $81(4.32 \%)$ & $6(0.32 \%)$ & $6(0.32 \%)$ & $2(0.11 \%)$ & $0(0 \%)$ \\
\hline & & & 1 & $2(0.11 \%)$ & $5(0.27 \%)$ & $6(0.32 \%)$ & $3(0.16 \%)$ & $0(0 \%)$ & $3(0.16 \%)$ & $9(0.48 \%)$ & $3(0.16 \%)$ & $6(0.32 \%)$ & $0(0 \%)$ \\
\hline & & a & 2 & $0(0 \%)$ & $0(0 \%)$ & $0(0 \%)$ & $0(0 \%)$ & $0(0 \%)$ & $0(0 \%)$ & $0(0 \%)$ & $0(0 \%)$ & $2(0.11 \%)$ & $0(0 \%)$ \\
\hline & & & 3 & $0(0 \%)$ & $0(0 \%)$ & $0(0 \%)$ & $0(0 \%)$ & $0(0 \%)$ & $0(0 \%)$ & $0(0 \%)$ & $1(0.05 \%)$ & $0(0 \%)$ & $0(0 \%)$ \\
\hline & & & 4 & $0(0 \%)$ & $0(0 \%)$ & $0(0 \%)$ & $0(0 \%)$ & $0(0 \%)$ & $0(0 \%)$ & $0(0 \%)$ & $0(0 \%)$ & $0(0 \%)$ & $0(0 \%)$ \\
\hline
\end{tabular}

CBCT-Cone beam computed tomography, M-molar; PM-premolar, BM-buccomesial, BD-buccodistal, P-palatal, B-buccal.

closest to the sinus maxillary, whereas the buccal and palatal roots of the first premolars were found to be farthest from the sinus maxillary, by the CBCT. However, when comparing the panoramic radiography with $\mathrm{CBCT}$, they differed greatly in the palatal roots of the second and first molars, which are teeth closer to the sinus cavity (Table 4).

The sample comprised 78 women and 31 men. However, considering gender, there was no significant correlation in the comparison of the qualitative and quantitative assessment of the relationship between maxillary tooth roots and the sinus ûoor in panoramic radiography and CBCT images.

\section{Discussion}

This goal of this study was to compare the qualitative and quantitative information provided by panoramic radiography to $\mathrm{CBCT}$ in order to assess the relation between maxillary sinus and the apices of the maxillary posterior teeth with or without some kind of pathology. In the literature, other authors used both imaging modalities to evaluate this topographic relationship ${ }^{3}$, but they reported some difficulty in evaluating this relationship in the presence of apical periodontitis perforating the sinus floor. Others ${ }^{22}$ investigated the reliability of periapical radiographs and orthopantomograms for exact detection of tooth root protrusion in the maxillary sinus by correlating the results with CBCT, obtaining a single score for each tooth using each imaging technique. In our study we included sound teeth in order to eliminate drawbacks when evaluating the sinus cortical. Also, we assessed each root for each tooth given a single score whether the teeth were single or multirooted as in one recent ${ }^{23}$.

Several studies have assessed the relationship between maxillary posterior teeth and the maxillary sinus $3,11-12,16-24$. In some of those studies, only one observer was used ${ }^{11-12,16,18-21}$, in others two observers were $u e^{7,17,23-24}$ and four observers were used in one study ${ }^{22}$. However only two of those studies ${ }^{3,22}$, however, carried out intra-and inter-observer analysis.

According to the majority of studies of roots with projection in the sinus cavities in the panoramic radiographs, only $39-57 \%$ showed protrusion into the maxillary sinus on CT scanning. This trend was reported in studies that reported that 2 of 38 subjects $(5 \%)$ had roots with protrusion into the sinus cavity by $\mathrm{CT}^{16}$. Bouquet et al. $(2004)^{12}$ clearly indicated 
that in certain cases the CT allowed the invalidation of the direct relation between the root to the maxillary sinus. However, 30 panoramic radiographs showed sinus projection on the tooth roots, while the CT showed that only 7 out of 30 cases had this relationship. The other 23 cases had the maxillary sinus far away from the roots of the teeth. One author ${ }^{11}$ noted that projections of roots into the sinus cavity in panoramic radiograph occurred on $39 \%$ of the cases on the average when compared to projections using CT, and the protrusion length is much shorter in CT than in those shown in the panoramic radiographs.

In the present study, we also found that 819 (43.7\%) out of 1,875 roots seemed to penetrate the maxillary sinus on panoramic radiographs, but only 80 (3.1\%) showed penetration of roots in CBCT. Furthermore, to the best of our knowledge, only one study ${ }^{23}$ examined each root of all teeth, as we did in the present study ${ }^{23}$. This closeness between the apices and maxillary sinus floor, which was found to be shorter in molars than in premolars, shows a concordance with the topographic anatomy, in which the anatomical sinus location itself is already a factor to be considered ${ }^{23}$. Other studies showed results for roots assessment just by CBCT without comparing with $2 \mathrm{D}$ images ${ }^{19,21}$, with one only providing assessment for the first and second molar ${ }^{19}$.

Studies have shown that the accuracy of the CBCT imaging for bone measurement around the apices of the posterior teeth is valid and provide great advantage in obtaining data on a non-invasive form, revealing high predisposition to CBCT of $0.4 \mathrm{~mm}$ with a standard deviation of $1.1 \mathrm{~mm}$ when compared with dissections ${ }^{24}$. Yoshimine et al. $(2012)^{20}$ recommended the use of CBCT because in their study it reliably demonstrates the $3 \mathrm{D}$ status of the morphological characteristics of the alveolar bone at the anticipated site of implant insertion. We agree with this conclusion especially in teeth that show root protrusion into the maxillary sinus in 2D images.

Furthermore, the apices of the first premolar were found beyond the maxillary sinus floor on both sides (mean: 6.54 $\mathrm{mm}$ ), as reported by some authors ${ }^{16,18,20}$, average of $7.05 \mathrm{~mm}$, $7.5 \mathrm{~mm}$ and $1.13 \mathrm{~mm}$, respectively. Moreover, the apices of buccomesial roots of the second molars were found to be below the maxillary sinus floor (mean: -0.21) agreeing with Eberhardt et al. (1992) ${ }^{16}$ and Yoshimine et al. (2012) ${ }^{20}$, who found an average of $1.97 \mathrm{~mm}$ and $0.82 \mathrm{~mm}$, respectively. These results are in disagreement with a previous study ${ }^{18}$ that found that the buccodistal root is the closest to the maxillary sinus floor. Ok et al. (2014) ${ }^{23}$ concluded the maxillary first premolars have no relationship with the maxillary sinus floor, but the maxillary second molars are closer to the sinus floor.

Even though the panoramic radiograph showed high concordance when the roots were below the maxillary sinus floor, there was a percentage of roots that was on the limit or beyond the maxillary sinus floor, approximately $40 \%$. These results corroborate with those of another study ${ }^{18}$, according to which when there is a percentage of $36 \%$ of teeth that are on the limit or beyond the maxillary sinus floor, CBCT should be used as the imaging modality suitable for such evaluations. In addition, Jung et al. (2012) ${ }^{19}$ reported a percentage of 41.2 of first and second molars on the limit or beyond the maxillary sinus floor.

Panoramic and periapical radiographs have the disadvantage of producing two-dimensional images of threedimensional structures. CBCT, on the other hand, is not the chosen method to evaluate individual teeth, but it a highly accurate imaging method in the evaluation of the apex-tooth relationship, especially in cases where the root has protrusion length in the maxillary sinus on radiographs. This was shown in our study, in which the observers found a high percentage of protruded roots in the maxillary sinus on panoramic radiography, and when evaluating the same roots using CBCT observed only contact with the maxillary sinus floor.

It is also worth mentioning that the study sample was formed recruiting random samples of subjects visiting the Oral Radiology Center of Piracicaba Dental School, UNICAMP, Brazil, while needing imaging has certain a convenience sample. This can be a problem when we analyzing a significant correlation between genders because of the difference of the number between males and females. However, this accounts for all consecutive patient studies, either clinical or radiological, with the latter unacceptable from an ethical point of view for exposing an external population to ionizing radiation.

A limitation in this study is the lack of analysis of histological samples. Since the oral radiologists evaluating the CBCT images were free to deal with the software and there were no standardized tests in reading the CBCT, they simply chose the window with better visualization of the apices in relation to the maxillary sinus floor.

It may be concluded that panoramic images enabled a high correlation when compared with CBCT in cases when the roots are not in contact with the maxillary sinus floor, and poor correlation when roots were in contact or within the maxillary sinus floor, underestimating values when the roots were projected in the maxillary sinus. For the panoramic radiography and $\mathrm{CBCT}$, the same result was obtained for both right and the left sides, considering the dental groups, except for the first molars. The present study also found the first premolar root tip to be the farthest, and the second molar buccomesial root tip to be closest to the sinus floor on both right and left sides.

\section{Acknowledgements}

We are grateful to CAPES for financial support on this research. The authors deny any conflict of interest.

\section{References}

1. Hauman $\mathrm{CH}$, Chandler NP, Tong DC. Endodontic implications of the maxillary sinus: a review. Int Endod J. 2002; 35: 127-41.

2. Wehrbein $H$, Diedrich $P$. The initial morphological state in the basally pneumatized maxillary sinus-a radiological-histological study in man [in german]. Fortschr Kieferorthop. 1992; 53: 254-62. 
3. Shahbazian M, Vandewoude C, Wyatt J, Jacobs R. Comparative assessment of panoramic radiography and $\mathrm{CBCT}$ imaging for radiodiagnostics in the posterior maxilla. Clin Oral Investig. 2014; 18: 293300.

4. Ariji Y, Ariji E, Yoshiura K, Kanda S. Computed tomographic indices for maxillary sinus size in comparison with the sinus volume. Dentomaxillofac Radiol. 1996; 25: 19-24.

5. Maillet M, Bowles WR, McClanahan SL, John MT, Ahmad M. Conebeam computed tomography evaluation of maxillary sinusitis. J Endod. 2011; 37: 753-7.

6. Kwak HH, Park HD, Yoon HR, Kang MK, Koh KS, Kim HJ. Topographic anatomy of the inferior wall of the maxillary sinus in Koreans. Int J Oral Maxillofac Surg. 2004; 33: 382-8.

7. Parrish NC, Warden PJ. A review of oro-antral communications. Gen Dent. 2010; 58: 312-7.

8. Watzek G, Bernhart T, Ulm C. Complications of sinus perforations and their management in endodontics. Dent Clin North Am. 1997; 41: 563-83.

9. Wehrbein H, Bauer W, Wessing G, Diedrich P. The effect of the maxillary sinus floor on orthodontic tooth movement [in german]. Fortschr Kieferorthop. 1990; 51: 345-51.

10. Daimaruya T, Takahashi I, Nagasaka H, Umemori M, Sugawara J, Mitani H. Effects of maxillary molar intrusion on the nasal floor and tooth root using the skeletal anchorage system in dogs. Angle Orthod. 2003; 73 : 158-66.

11. Sharan A, Madjar D. Correlation between maxillary sinus floor topography and related root position of posterior teeth using panoramic and crosssectional computed tomography imaging. Oral Surg Oral Med OralPathol Oral RadiolEndod. 2006; 102: 375-81.

12. BouquetA, Coudert JL, Bourgeois D, Mazoyer JF, Bossard D. Contributions of reformatted computed tomography and panoramic radiography in the localization of third molars relative to the maxillary sinus. Oral Surg Oral Med Oral Pathol Oral Radiol Endod. 2004; 98: 342-7.

13. Tyndall DA, Price JB, Tetradis S, Ganz SD, Hildebolt C, Scarfe WC; American Academy of Oral and Maxillofacial Radiology. Position statement of the American Academy of Oral and Maxillofacial Radiology on selection criteria for the use of radiology in dental implantology with emphasis on cone beam computed tomography. Oral Surg Oral Med Oral Pathol Oral Radiol. 2012; 113: 817-26.

14. Scarfe WC, Farman AG, Sukovic P. Clinical applications of cone-beam computed tomography in dental practice. J Can DentAssoc. 2006; 72: 75-80.

15. Liang $X$, Jacobs R, Hassan B, Li L, Pauwels R, Corpas L, et al. A comparative evaluation of Cone Beam Computed Tomography (CBCT) and Multi-Slice CT (MSCT) Part I. On subjective image quality. Eur J Radiol. 2010; 75: 265-9

16. Eberhardt JA, Torabinejad M, Christiansen EL. A computed tomographic study of the distances between the maxillary sinus floor and the apices of the maxillary posterior teeth. Oral Surg Oral Med Oral Pathol. 1992; 73 : 345-6.

17. Ariji Y, Obayashi N, Goto M, Izumi M, Naitoh M, Kurita K, et al. Roots of the maxillary first and second molars in horizontal relation to alveolar cortical plates and maxillary sinus: computed tomography assessment for infection spread. Clin Oral Investig. 2006; 10: 35-41.

18. Kilic C, Kamburoglu K, Yuksel SP, Ozen T. An Assessment of the Relationship between the Maxillary Sinus Floor and the Maxillary Posterior Teeth Root Tips Using Dental Cone-beam Computerized Tomography. Eur J Dent. 2010; 4: 462-7.

19. Jung $\mathrm{YH}, \mathrm{Cho} \mathrm{BH}$. Assessment of the relationship between the maxillary molars and adjacent structures using cone beam computed tomography. Imaging Sci Dent. 2012; 42: 219-24.

20. Yoshimine S, Nishihara K, Nozoe E, Yoshimine M, Nakamura N. Topographic analysis of maxillary premolars and molars and maxillary sinus using cone beam computed tomography. Implant Dent. 2012; 21: 528-35.
21. Pagin O, Centurion BS, Rubira-Bullen IR, Alvares Capelozza AL. Maxillary sinus and posterior teeth: accessing close relationship by conebeam computed tomographic scanning in a Brazilian population. J Endod. 2013; 39: 748-51.

22. Hassam BA. Reliability of periapical radiographs and orthopantomograms in detection of tooth root protrusion in the maxillary sinus: correlation results with cone beam computed tomography. J Oral Maxillofac Res. 2010; 1: e6.

23. Ok E, Güngör E, Colak M, Altunsoy M, Nur BG, Aðlarci OS. Evaluation of the relationship between the maxillary posterior teeth and the sinus floor using cone-beam computed tomography. Surg Radiol Anat. 2014; 36: 907-14.

24. Howe RB. First molar radicular bone near the maxillary sinus: a comparison of CBCT analysis and gross anatomic dissection for small bony measurement. Oral Surg Oral Med Oral Pathol Oral Radiol Endod. 2009; 108: 264-9. 